\title{
PAHAM DAN ALIRAN AKIDAH DALAM ISLAM
}

Muh. Ilham Usman

STAIN Majene

ilhamusman@stainmajene.ac.id

\begin{abstract}
Abstrak
Tulisan ini menyajikan hasil penelitian tentang munculnya sebab-sebab aliran dan paham akidah dalam Islam. Penelitian ini menggunakan metode kajian pustaka untuk meneropong atau memotret lahirnya aliran dan paham akidah dalam dunia Islam. Pengumpulan data dilakukan dengan menelaah sumber primer dan sekunder dalam mendukung kajian munculnya aliran dan paham akidah yang berada di tengah-tengah umat Islam saat ini. Hasil telaah dan penelitian menemukan bahwa telah sepakat para ulama dan cendekiawan Islam bahwa aliran dan paham akidah dalam Islam yang pertama kali muncul adalah aliran Khawarij, Murji'ah, Syi'ah, Mu'tazilah, Asy'ariah dan Maturidiyah. Akan tetapi, dalam tulisan ini belum membahas aliran Syi'ah dan juga aliran Maturidiyah.
\end{abstract}

\section{Kata Kunci: Khawarij, Murji'ah, Mu'tazilah dan Asy'ariyah}

\section{A. Pendahuluan}

Kemunculan paham dan aliran-aliran teologi dalam Islam tidaklah dapat dilepaskan dari pertikaian politik. Ini dapat kita lacak ketika terbunuhnya Khalifah Usman bin Affan ra., banyak kalangan yang tidak menerima kematian beliau. Olehnya itu, kebanyakan para sahabat menuntut kepada pemerintahan Ali bin Abi Thalib untuk segera menghukum pelaku pembunuhan Usman bin Affan. Apatah lagi, ada indikasi jika khalifah Ali bin Abi Thalib terlibat dalam wafatnya khalifah Utsman bin Affan dikarenakan

Ketika Ali bin Abi Thalib sebagai khalifah, segera ia mendapat tantangan dari pemukapemuka yang ingin menjadi khalifah yakni Thalhah dan Zubair bin Awwan (kakak ipar Aisyah, suami dari Asma' bin Abi Bakr) yang disokong oleh Aisyah, puncaknya terjadi perang Jamal (tahun $35 \mathrm{H} / 656 \mathrm{M}$ ) antara pasukan khalifah Ali dengan pasukan 'Aisyah-Thalhah-Zubair. Yang dimenangkan oleh khalifah Ali bin Abi Thalib.

Adapun tantangan kedua, berasal dari gubernur Damaskus Muawiyah bin Abi Sufyan yang tidak mau mengakui kekhalifahan Ali bin Abi Thalib dan menuntut untuk menghukum 
para pembunuh khalifah Utsman bin Affan, serta menuduh Ali bin Abi Thalib terlibat dalam kematian khalifah Utsman bin Affan. Hal ini disebabkan salah satu pemuka pemberontak adalah Muhammad bin Abi Bakr yang juga merupakan saudara Aisyah adalah anak angkat khalifah Ali bin Abi Thalib. Dan membuat pihak Muawiyah bin Abi Sufyan kecewa karena Muhammad bin Abi Bakr diangkat oleh Khalifah Ali bin Abi Thalib menjadi Gubernur Mesir dikemudian hari menggantikan Abdullah bin Saad (Saudara sesusuan Utsman bin Affan). ${ }^{1}$ Pada perang Jamal, Muhammad bin Abu Bakr berada di pihak 'Ali melawan Aisyah. Muhammad bin Abu Bakr di kemudian hari di bunuh oleh Muawiyah secara tragis. ${ }^{2}$ Puncak dari ketidaksetujuan pihak Muawiyah bin Abi Sufyan terhadap Ali bin Abi Thalib yakni terjadinya perang Shiffin (tahun $36 \mathrm{H} / 657 \mathrm{M}$ ) antara pihak khalifah Ali dan gubernur Muawiyah bin Abi Sufyan. ${ }^{3}$

Akhir dari dari peristiwa ini adalah terjadinya negoisasi, yang justru dimenangkan oleh pihak Muawiyah bin Abi Sufyan. Kelompok Khawarij merupakan kelompok pertama yang tidak sepakat dengan negoisasi tersebut. Kelompok ini mengatakan bahwa tidak beriman orang yang menerima keputusan arbitrase, karena siapa yang tidak menentukan hukum dengan apa yang telah di turunkan Allah adalah kafir. Dari pernyataan kelompok Khawarij inilah, menimbulkan reaksi dari berbagai kelompok yang tidak setuju dengan pendapat tersebut, seperti Murji'ah, Mu’tazilah, Asy’ariyyah, Maturidiyyah Samarkand dan Maturidiyyah Bukhara.

Saling kafir-mengkafirkan pun menjadi sebuah realitas yang tak dapat disangkal pada masa ini, bahkan banyak nyawa kaum muslimin melayang dalam mempertahankan konsep dan pendirian tersebut. Dalam sejarah tercatat kaum Khawarij melakukan tindak kekerasan kepada siapapun yang tidak bersama mereka, baik dalam konsep maupun tindakannya. Secara akal manusiawi, tindakan yang dilakukan oleh kelompok Islam terhadap sesama muslim adalah hal

\footnotetext{
${ }^{1}$ Harun Nasution, Teologi Islam: Aliran-Aliran Sejarah Analisa Perbandingan (Jakarta: UI Press, 1986)., h. 5.

${ }^{2}$ O Hashem, Saqifah Suksesi Sepeninggal Rasulullah Saw: Awal Perselisihan Umat (Depok: YAPI, 1989)., h. 39.

${ }^{3}$ Harifuddin Cawidu, Konsep Kufr Dalam Al-Qur'an: Suatu Kajian Teologis Dengan Pendekatan Tafsir Tematik, 1st edn (Jakarta: Bulan Bintang, 1991)., h. 9.
} 
yang di luar batas. Yang berlalu, biarlah berlalu. Saling menyalahkan mestilah diretas, mana kelompok yang benar dan mana yang salah, tak perlu lagi dipermasalahkan. Akan tetapi, mengambil hikmah dan pelajaran dari kelompok yang bertikai dalam rangka memahami sejarah masa lalu sangatlah urgen, agar dikemudian hari tidak ada lagi terjadi kafirmengkafirkan, menghakimi kelompok lain dengan istilah "murtad" dan lain sebagainya.

\section{Pembahasan}

Asy-syahrastani menjelaskan bahwa faktor terjadinya perbedaan pandangan yang menyebabkan melahirkan aliran-aliran akidah Islam, karena beberapa hal, yakni (1). Persoalan sifat dan ke-Esa-an Allah Swt. Sebagian ada yang menerima sifat Allah Swt dan sebagian pula ada yang menolaknya. Aliran Asy'ariyah, Qaramitah dan Mu'tazilah berbeda pendapat mengenai sifat yang wajib, mustahil dan jaiz. (2). Persoalan keadilan Allah Swt, qadha dan qadhar. Para ahli kalam berbeda pendapat tentang persoalan tersebut. (3). Persoalan wa'ad, wa'id dan asma Allah Swt. Para ulama kalam juga mempunyai pendapat yang berbeda, di antaranya para ulama Murji'ah, Asy'ariyah dan Mu'tazilah. (4). Serta persoalan akal dan wahyu, kehendak Allah Swt dan kehendak manusia. Yang terakhir ini diperdebatkan oleh aliran Syi'ah, Khawarij, Mu'tazilah dan Asy'ariyah. ${ }^{4}$

Gagasan atau pemikiran adalah refleksi terhadap pemahaman terhadap Al-Qur'an, hadist, fenomena alam, sosial, ekonomi, politik dan budaya yang dikeluarkan oleh seorang intelektual. Olehnya itu, adalah memang benar, jikalau gagasan atau pemikiran akan terus ada dan eksis, walaupun aliran dan tokoh pencetusnya telah tiada atau terpinggirkan ke jurang kemanusiaan yang paling jauh. Begitu juga halnya dengan gagasan yang dicetuskan oleh aliran Khawarij, Syi’ah, Murji'ah, Mu’tazilah, Asy’ariyyah, Maturidiyyah Samarkand dan Maturidiyyah Bukhara, akan terus ada dan langgeng sepanjang dunia ini masih berputar dan manusia menjalani hidup dan kehidupan ini. Sederhananya, gagasan atau pemikiran tak lekang diterpa terik matahari dan tak luntur dibasahi air hujan, ia akan terus muncul selama ia diperbincangkan atau diperdebatkan.

${ }^{4}$ Asy-Syahrastani, Al-Milal Wa Nihal Alih Bahasa Oleh Asywandie Syukur (Surabaya: Bina Ilmu, 2000)., h. 4-5. 
Menulis atau membaca ulang sejarah pemikiran Islam serta terus-menerus melakukan pengkajian terhadapnya adalah sebuah keniscayaan yang harus ditempuh, agar di kemudian hari dapat memberi pelajaran dan hikmah dalam menyongsong hidup yang aman, makmur, damai dan tentram, sebagaimana cita-cita agama Islam, yakni menciptakan masyarakat yang adil, tentram, sejahtera dan makmur. Meminjam bahasa Wahid Hasyim, kita harus memahami masa lalu, melihat masa kini untuk merancang masa depan.

Persoalan iman dan kufur adalah persoalan esensial bagi seorang muslim, karena berkaitan dengan pertanggungjawabannya di akhirat kelak. Olehnya itu, perdebatan siapa yang mukmin dan siapa pula yang kafir serta apa yang menjadi parameternya menjadi inti dari permasalahan ini. Mempertahankan identitas diri adalah sesuatu yang harus, mereka tidak mau di cap kafir hanya gara-gara sesuatu hal, dan tak segan-segan pula mencari dalil-dalil untuk menguatkan bahwasanya mereka tidak kafir, tetapi mukmin. Adapun aliran-aliran akidah Islam yang pernah muncul, eksis, dan berpengaruh di zamannya. Dan ada juga muncul, hingga tak lama tengelam oleh zaman.

\section{Aliran Khawarij}

Aliran ini lahir akibat dari ketidaksetujuan atas arbitrase/negosiasi atau tahkim yang dilakukan oleh khalifah Ali terhadap penyelesaian persengketaan khalifah dengan Muawiyah Ibn Abi Sufyan, sehingga mereka memisahkan diri dari kelompok khalifah Ali dan menganggap orang-orang yang terlibat dari peristiwa tersebut adalah orang-orang yang memutuskan perkara tidak dengan hukum Allah Swt. Menurut Harun Nasution bahwa jumlah pengikut kaum Khawarij ketika memisahkan diri dari kelompok khalifah Ali bin Abi Thalib yakni berjumlah 12.000 orang serta memilih 'Abdullah ibn Wahb al-Rasidi menjadi imam mereka sebagai ganti dari khalifah Ali bin Abi Thalib. ${ }^{5}$ Olehnya itu, mereka termasuk orangorang yang berbuat salah dan berdosa besar. Maka kaum Khawarij memandang bahwa 'Ali, Muawiyah, Amr Ibn al-'Ash, Abu Musa al-Asy’ari dan lain-lain yang menerima arbitrase adalah kafir, ${ }^{6}$ ini sesuai dengan firman Allah Swt dalam Surah al-Ma'idah ayat 44:

\footnotetext{
5 Nasution, Teologi Islam: Aliran-Aliran Sejarah Analisa Perbandingan., h. 11.

${ }^{6}$ Nasution, Teologi Islam: Aliran-Aliran Sejarah Analisa Perbandingan., h. 6
} 


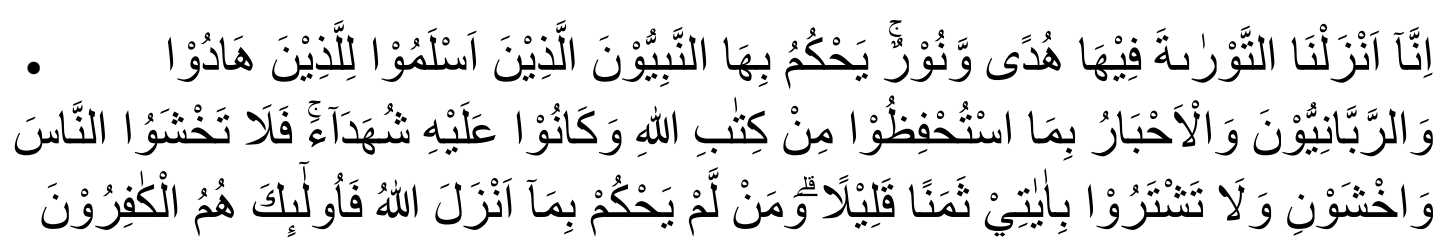

Terjemahnya

Sesungguhnya Kami telah menurunkan kitab Taurat di dalamnya (ada) petunjuk dan cahaya (yang menerangi), yang dengan kitab itu diputuskan perkara orang-orang Yahudi oleh nabi-nabi yang menyerah diri kepada Allah, oleh orang-orang alim mereka dan pendeta-pendeta mereka, disebabkan mereka diperintahkan memelihara KitabKitab Allah dan mereka menjadi saksi terhadapnya. karena itu janganlah kamu takut kepada manusia, (tetapi) takutlah kepada-Ku. dan janganlah kamu menukar ayat-ayat$\mathrm{Ku}$ dengan harga yang sedikit. Barangsiapa yang tidak memutuskan menurut apa yang diturunkan Allah, Maka mereka itu adalah orang-orang yang kafir.

Dengan ayat inilah, mereka mengambil simbol la hukma illa lillah, maka orang-orang yang tidak mengambil hukum dari Allah Swt, termasuk orang yang berdosa besar dan kafir. Atas peristiwa arbitrase inilah, aliran Khawarij mulai memunculkan persoalan teologi yakni berkaitan dengan pelaku dosa besar dan stigma yang diperolehnya.

Dalam perkembangan selanjutnya, aliran Khawarij ini menggiring persoalan ke arah konsep kufr yakni berusaha menentukan dengan pasti siapakah orang-orang kafir itu? Dan siapa pulalah mereka yang termasuk masyarakat muslim ideal?. ${ }^{7}$ Inilah pertanyaan-pertanyaan yang menyangkut pemikiran teologi Khawarij dalam perkembangan selanjutnya. Di dalam aliran Khawarij berkembang beberapa sekte dengan pelbagai corak pemikirannya tersendiri. Diantaranya, sekte Muhakkimah berpendapat bahwa siapapun yang melakukan dosa atau ketidaktaatan terhadap perintah Allah, harus dikecam sebagai orang yang sungguh-sungguh kafir. Sedangkan sekte Azariqah ${ }^{8}$ berpendapat bahwa orang-orang yang berdosa besar,

\footnotetext{
${ }^{7}$ Toshihiko Izutsu, The Concept of Belief in Islamic Theology: A Semantical Analysis of Iman Anda Islam Diterjemahkan Oleh Agus Fahri Husein Dengan Judul Konsep Kepercayaan Dalam Teologi Islam: Analisis Semantik Iman Dan Islam (Yogyakarta: Tiara Wacana, 1994)., h. 12.

${ }^{8}$ Sekte ini dikenal sebagai ekstremis khawarij. Kelompok ini mempunyai tiga ciri khas yakni pertama, semua orang muslim yang tidak mengikuti pendapat mereka sampai yang sekecil-kecilnya adalah Musyrik. Kedua, semua orang sekalipun setuju dengan Azariqah secara teori, namun tidak berhijrah ke perkampungan mereka adalah Musyrik. Ketiga, istri-istri dan anak-anak dari orang Musyrik tersebut juga Musyrik. Dan kesemuanya ini secara sah dapat di bunuh dan hartanya di rampas. Lihat Izutsu.
} 
bukanlah kafir tetapi musyrik-politeis. Sedangkan sekte Najdiyyah ${ }^{9}$ berpendapat bahwa orang berdosa besar yang menjadi kafir dan kekal dalam neraka hanyalah orang Islam yang tak sefaham dengan golongannya, sedangkan pengikutnya jika mengerjakan dosa besar, betul akan mendapat siksaan, tetapi bukan dalam neraka kemudian akan masuk surga.

Dalam sejarah Islam, golongan Khawarij adalah golongan yang kuat ibadahnya, akan tetapi dalam perbedaan pendapat, sangat berbanding terbalik. Berikut ini adalah suatu kisah yang ditulis Imam Muhammad Abu Zahrah dalam bukunya yang berjudul "Tarikh alMadzahib al-Islamiyyah" yang dikutip dari kitab al-kamil karya al-Mubarrad tentang kontroversialnya sikap kaum Khawarij. Di antara perangai mereka yang sangat kontroversial ialah mereka menangkap seorang Muslim dan seorang Nasrani. Orang Muslim mereka bunuh, sedangkan orang Nasrani mereka nasihati secara baik, dengan mengatakan: "Peliharalah janji nabi kamu". Mereka kemudian bertemu dengan 'Abdullah ibn Khabbab yang sedang membawa al-Qur'an bersama istrinya yang sedang hamil. Mereka bertanya kepada 'Abdullah: "Yang sedang engkau bawa itu memerintahkan kami untuk membunuhmu". Kemudian pertanyaannya dilanjutkan: “Apa pendapatmu tentang Abu Bakar dan 'Umar?”, Abdullah memuji keduanya. Mereka bertanya lagi: "Bagaimana pendapatmu tentang 'Ali sebelum peristiwa tahkim dan tentang 'Utsman selama 6 tahun pertama masa pemerintahannya?", Ia juga memuji keduanya. Mereka terus bertanya: "Bagaimana pendapatmu tentang tahkim itu?. Abdullah menjawab: "Menurut pendapat saya 'Ali lebih paham tentang al-Qur'an, lebih bertakwa, dan lebih jauh pandangannya di banding kamu”. Kemudian mereka berkata: "Engkau tidak perlu mengikuti orang atas dasar nama-nama mereka". Selanjutnya mereka membawa 'Abdullah ibn Khabbab ke tepi sungai, lalu menyembelihnya. Dalam peristiwa lain, mereka menawar kurma seorang pria Nasrani. Karena merasa takut, pria Nasrani ini berkata: “Ambillah untuk kamu”. Namun, mereka berkata: "Demi Allah, kami tidak akan mengambilnya kecuali jika kami bayar". Pria Nasrani itu berkomentar: “Alangkah anehnya, mengapa kalian membunuh orang seperti 'Abdullah ibn Khabbab, tetapi kamu tidak mau menerima kurma dari kami tanpa membayar?"

\footnotetext{
${ }^{9}$ Nasution, Teologi Islam: Aliran-Aliran Sejarah Analisa Perbandingan., h. 16.
} 


\section{Aliran Murji’ah}

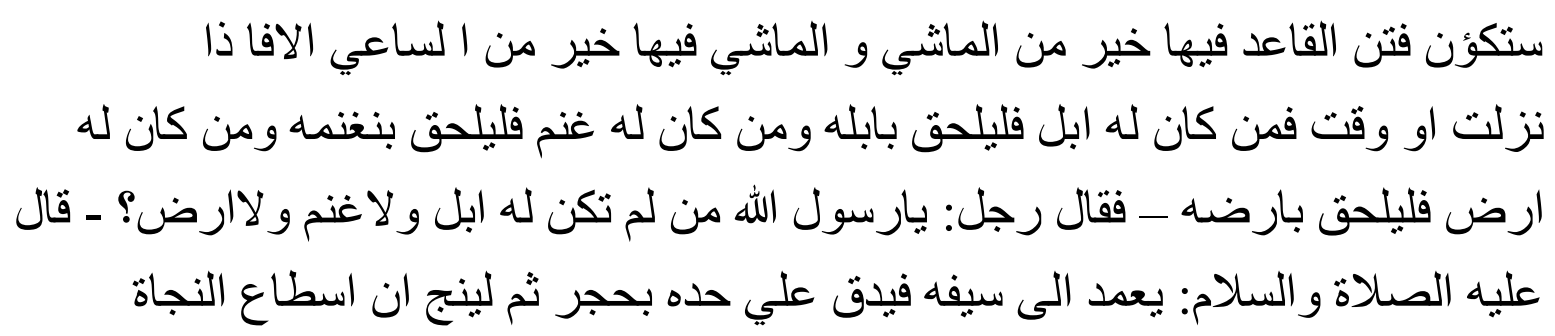

Terjemahan

(Nanti akan timbul berbagai fitnah, dimana orang yang duduk lebih baik daripada yang berjalan; yang berjalan lebih baik daripada yang berlari. Jika peristiwa itu tiba, maka orang yang memiliki unta hendaklah memegang untanya; yang memiliki kambing hendaklah memegang kambingnya, dan yang memiliki tanah hendaklah bertahan di tanahnya. Seorang laki-laki bertanya: "Ya Rasulullah, bagaimana orang yang tidak memiliki unta, kambing, ataupun tanah?" Jawab Nabi, "Hendaklah ia mengambil pedangnya dan meletakkannya ke batu, kemudian hendaklah ia menyelamatkan diri, jika mampu untuk itu). ${ }^{10}$

Dengan dalil inilah, kaum Murji'ah mengambil sikap tidak mau menetapkan hukum kelompok mana yang paling benar di antara dua kelompok yang saling bertikai. Karena tidak mempunyai sikap dalam pertikaian politik tersebut, maka di dalam sejarah Islam diberi predikat sebagai aliran teologi yang menjadi pendukung dari khalifah Umayyah ibn Abi Sufyan. ${ }^{11}$ Sebagai pendukung dinasti yang berkuasa, maka tidaklah heran jikalau pelbagai corak pemikirannya “meng-counter" pemikiran Khawarij dan Syi'ah yang getol mengkritisi dan "mengguncang" tampuk kekuasaan Khalifah Umayyah. Ini dapat kita lihat, bagaimana corak pemikiran Murji'ah yang lebih berorientasi kepada konsep iman. Aliran ini mengatakan bahwa seorang mukmin (pemimpin) tidaklah kafir, selama ia masih membenarkan eksistensi Allah Swt, di dalam hatinya. Mereka sepakat bahwasanya iman adalah mengetahui Allah dan

${ }^{10}$ Muhammad Abu Zahrah, Tarikh Al-Madzahib Al-Islamiyyah Diterjemahkan Oleh Abd. Rahman Dan Ahmad Qarib Dengan Judul Aliran Politik Dan'Aqidah Dalam Islam (Jakarta: Logos, 1996)., h. 144.

11 Nashr Hamid Abu Zaid, Al-Ittijah Al- 'Aqli Fi Al-Tafsir: Dirasah Fi Qadhiyyat Al-Majaz Fi Al-Qur'an 'Inda Al-Mu'Tazilah Diterjemahkan Oleh Abdurrahman Kasdi Dan Hamka Hasan Dengan Judul Menalar Firman Allah: Wacana Majaz Dalam Al-Qur'an Menurut Mu’tazilah (Jakarta: Mizan, 2003)., h. 31. 
membenarkan-Nya tanpa melalui perbuatan. Secara eksplisit, kita dapat mengatakan bahwa khalifah Muawiyah bukanlah pelaku dosa besar dan kafir, akan tetapi termasuk seorang mukmin dan wilayah kekuasaannya berada dalam dar al-iman

Terlepas dari wacana di atas, Murji'ah tidak menjadikan perbuatan sebagai tolak ukur iman. Mereka berpendapat bahwa "iman adalah tasdhiq keberadaan Allah Swt di dalam hati sedangkan kufur adalah mendustakan keberadaannya, soal dosa yang dilakukannya, terserah kepada Allah Swt untuk mengampuni atau tidak mengampuninya". ${ }^{12}$ Menurut aliran ini, iman dan kufur adalah urusan di dalam hati, tidak nampak dalam perbuatan kehidupan sehari-hari. Apabila seseorang telah percaya dan yakin akan adanya Allah Swt, maka orang itu telah dinyatakan beriman, walaupun tindak dan perilakunya tidak mencermin seseorang itu beriman. Bagi orang Islam yang melakukan dosa besar bukanlah kafir tetapi mukmin dan tidak akan kekal dalam neraka.

Dalam perkembangannya, aliran Murji'ah terbagi dua, yakni Murji'ah ekstrim dan Murji'ah moderat. Aliran Murji'ah ekstrem, seperti al-Jahmiah berpendapat bahwa orang Islam yang percaya pada Allah dan kemudian menyatakan kekufuran secara lisan tidaklah menjadi kafir, karena iman dan kufr tempatnya hanyalah dalam hati, bukan bagian dari tubuh manusia. ${ }^{13}$ Al-Salihiah berpendapat bahwa iman adalah mengetahui Allah dan kufr adalah tidak tahu pada Allah. Olehnya itu, ibadah mahdhah seperti shalat, zakat, puasa, dan haji bukanlah ibadah kepada Allah melainkan hanya kepada Allah.

Di sisi lain, aliran Murji'ah moderat berpendapat bahwa iman adalah pengakuan dalam hati tentang ke-Esaan Allah dan tentang kebenaran Rasul-rasul Allah serta segala apa yang mereka bawa. Mengucapkannya dengan lisan dan mengerjakan rukun-rukun Islam merupakan cabang dari iman. Orang yang berdosa besar, jika meninggalkan dunia tanpa taubat, nasibnya terletak di tangan Allah. Ada kemungkinan Allah akan mengampuni dosa-dosanya, tetapi ada pula kemungkinan Allah tidak akan mengampuni dosa-dosanya dan akan menyiksanya sesuai dengan dosa-dosa yang dibuatnya dan kemudian baru ia dimasukkan ke dalam surga, karena ia tak mungkin akan kekal tinggal dalam neraka. Pendapat ini diakui sendiri oleh al-Bazdawi

\footnotetext{
${ }^{12}$ M. Yusran Asmuni, Ilmu Tauhid (Jakarta: Raja Grafindo Persada, 1994)., h. 157.

${ }^{13}$ Nasution, Teologi Islam: Aliran-Aliran Sejarah Analisa Perbandingan., h. 26.
} 
dengan mengatakan: “Kaum Murji’ah pada umumnya sependapat dengan ahli sunnah wal jama'ah"

\section{Aliran Mu'tazilah}

Aliran ini muncul pada masa pemerintahan Bani Umayyah, tetapi baru pada masa pemerintahan 'Abbasiyyah, khususnya pada masa Khalifah al-Ma'mun, menghebohkan pemikiran Islam. Tetapi pada umumnya, ulama berpendapat bahwa tokoh Washil ibn 'Atha' (lahir di Madinah, $81 \mathrm{H}$ dan wafat pada tahun $131 \mathrm{H}$ ) sebagai pencetus aliran ini. Washil bin 'Atha' lahir dari seorang maula keturunan Iran. Pada era pemuda Washil bin 'Atha' pernah ikut dalam medan perang. Dari sinilah, ia banyak mengenal adat-istiadat, ragam bahasa dan bangsa, hingga akhirnya menetap di Basrah sebagai bandar pelabuhan tersibuk di teluk Persia dan belajar kepada imam Hasan al-Bashri. ${ }^{14}$ Menurut Ignaz Goldziher, pendiri Mu'tazilah ini dikenal sebagai orang yang zuhud, sering melaksanakan shalat tahajud sepanjang malam dan telah melaksanakan ibadah haji selama empat kali dengan berjalan kaki. ${ }^{15}$

Menurut al-Syahrastani yang dikutip oleh Harun Nasution mengatakan bahwa awal mula nama "Mu'tazilah" berasal peristiwa yang terjadi antara Washil bin 'Atha' dan 'Amr ibn 'Ubaid terhadap gurunya Hasan al-Bashri. Suatu hari ada orang yang bertanya berkaitan kedudukan orang berdosa besar, apakah termasuk kafir atau mukmin? Ketika Hasal al-Bashri berfikir, Washil pun dengan sigap mengeluarkan pendapatnya dengan mengatakan bahwa kedudukan orang berdosa besar bukanlah mukmin dan bukan pula kafir, tetapi mengambil posisi di antara keduanya; tidak mukmin dan tidak kafir. Setelah menjawab pertanyaan orang tersebut, Washil bin 'Atha' berdiri dan menjauhkan diri dari gurunya Hasan al-Bashri pergi ke sudut masjid yang lain. Kemudian Hasan al-Bashri mengatakan: "i’tazala 'anna” (Washil menjauhkan diri dari kita). ${ }^{16}$

Beliau menolak pendapat Khawarij yang menetapkan hukum terhadap pelaku dosa besar sebagai kafir dan tidak sepakat dengan pendapat Murji'ah yang menyatakan orang

${ }^{14}$ Analiansyah, 'Peran Akal Dan Kebebasan Bertindak Dalam Filsafat Ketuhanan Mu'tazilah', Jurnal Subtantia, 15.1 (2013). , h. 92-93. 1981)., h. 87.

${ }^{15}$ Ignaz Goldziher, Introduction to Islamic Theologi and Law (New Jersey: Princeton University Press,

${ }^{16}$ Nasution, Teologi Islam: Aliran-Aliran Sejarah Analisa Perbandingan., h. 38. 
tersebut sebagai mukmin dan juga keluar dari majelis gurunya Hasan al-Basri ${ }^{17}$ yang menyatakan bahwa pelaku dosa besar sebagai orang munafik. Ia pun mengambil tempat dan mengeluarkan pendapat bahwasanya pelaku dosar itu adalah fasiq (Manzilah bain alManzilatain). Washil ibn 'Atha' berpendapat bahwa kata mukmin merupakan sifat baik dan nama pujian yang tak dapat diberikan kepada fasiq (orang mukmin, tetapi sudah jauh dalam agama), dengan dosa besarnya. Begitu pula dengan predikat kafir tidaklah dapat disandangkan kepadanya, karena ia masih mengucapkan syahadat dan mengerjakan perbuatan-perbuatan baik. ${ }^{18}$ Orang serupa ini, kalau meninggal dunia tanpa taubat, akan kekal dalam neraka, hanya saja siksaannya lebih ringan dari siksaan yang diterima orang kafir.

Menurut A. Hanafi yang dikutip oleh Zulhelmi bahwa golongan teologi Islam Mu'tazilah lebih memusatkan perhatiannya untuk penyiaran Islam melalui dialogis filosofis dan membantah alasan-alasan orang yang memusuhi Islam melalui argumentasi logis. ${ }^{19}$ Mu'tazilah adalah golongan yang membawa persoalan-persoalan teologi yang lebih mendalam dan bersifat filosofis daripada persoalan-persoalan yang dibawa kaum Khawarij dan Murji'ah. ${ }^{20}$

Paham Mu'tazilah sejalan dengan paham Qadariyah yang memusatkan kebebasan manusia dalam berbuat dan menentukan nasib sendiri dalam menjalani kehidupan dunia. Oleh karena itu, paham Qadariyah sedikit-banyaknya tak bisa dilepaskan dari corak pikir Mu’tazilah yang sepakat bahwasanya manusia merupakan ciptaan Allah Swt yang mempunyai kehendak bebas dan berdaulat dalam menentukan langkah kehidupannya untuk menciptakan peradaban.

\footnotetext{
${ }^{17}$ Hasan al-Bashri, apabila di runut dari status sosialnya, adalah seorang budak dari keluarga Maisangolongan budak kaum Anshar. Ibunya bernama Khairah, budak milik Ummu Salamah, Istri Rasulullah Saw. Serangan Umayyah terhadap Irak mencapai puncaknya di era 'Abd al-Malik ibn Marwan dan Gubernur Irak kala itu adalah Hajjaj ibn Yusuf. Kuatnya tekanan dari Hajjaj ketika berinteraksi dengan Hasan al-Bashri dan para pengikutnya membuat Hasan al-Bashri dan para pengikut-setianya lebih memilih jalan rekonsiliasi dan menyembunyikan sikap (taqiyyah), minimal di hadapan Al-Hajjaj dan pejabat yang lainnya. Meskipun demikian, mereka tetap mendeklarasikan pemikirannya pada para pengikutnya yang lain dengan tegas. Hasan al-Bashri lebih memilih taqiyyah ketika berbicara tentang 'Ali ra., walaupun ia bukan orang Syi'ah. Kecintaannya terhadap 'Ali ra. menjadi penyebab Bani Umayyah menyiksanya. Lihat Abu Zaid., h. 49-55.

${ }^{18}$ Nasution, Teologi Islam: Aliran-Aliran Sejarah Analisa Perbandingan., h. 43.

${ }^{19}$ Zulhelmi, 'Epistemologi Pemikiran Mu’tazilah Dan Pengaruhnya Terhadap Perkembangan Pemikiran Islam Di Indonesia’, Intizar, 20.1 (2014)., h. 3.

${ }^{20}$ Nasution, Teologi Islam: Aliran-Aliran Sejarah Analisa Perbandingan., h. 38.
} 
Pendiri Mu'tazilah Washil bin 'Atha' pernah menyatakan pendiriannya bahwa Tuhan bersifat bijaksana dan adil, Dia tidak berbuat jahat dan berlaku zalim. Tuhan tidak menghendaki manusia berbuat hal-hal yang bertentangan dengan perintah-Nya, manusia sendirilah yang sebenarnya mewujudkan perbuatan baik atau perbuatan jahat. Untuk terwujudnya perbuatanperbuatan tersebut, Tuhan telah memberikan daya dan kekuatan kepada manusia. Tuhan tidak menurunkan perintah kepada manusia untuk berbuat sesuatu kalau manusia tidak mempunyai daya dan kekuatan untuk berbuat. ${ }^{21}$ Secara sederhana, kalangan Mu'tazilah mengatakan bahwa tauhid adalah sifat terpenting dari zat Tuhan, sedang keadilan merupakan sifat terpenting dalam perbuatan Tuhan. ${ }^{22}$

Di samping itu, tokoh-tokoh aliran Mu’tazilah mampu menciptakan ilmu baru dalam dunia Islam yang hingga kini menjadi kekayaan intelektual dan tak bisa dilupakan peranannya dalam meninggikan agama Islam yakni ilmu balaghah. Ilmu yang terlahir dari penggalian dari ayat-ayat mutasyabihat dalam Al-Qur'an dan diakui serta diterima oleh mazhab-mazhab dalam Islam. ${ }^{23}$ Keberanian Zamakhsari memberikan makna-makna takwil terhadap ayat-ayat mutasyabihat di dalam al-Qur'an dalam kitabnya al-Kasysyaf 'an Haqaiqil Tanzil yang melahirkan ilmu pengetahuan baru. Walaupun di sisi lain, paham Mu'tazilah bersama dengan pemerintahan Khalifah al-Ma'mun melakukan mihnah kepada para ulama berkaitan dengan kemakhlukan Al-Qur'an. ${ }^{24}$

\section{Aliran Asy'ariah}

Peletak dasar aliran ini adalah Abu Hasan al-Asy'ari (Lahir di Basrah, 260 H/873 M, dan wafat di Bagdad, 324 H/935 M), setelah melakukan diskusi dengan gurunya dari kalangan Mu'tazilah, Abu 'Ali al-Jubba'I yang berkaitan dengan kewajiban berbuat terbaik bagi Allah. Setelah melakukan diskusi dengan gurunya, ia pun berdiam di rumahnya dan mencoba membandingkan dalil-dalil kedua kelompok tersebut. Dan akhirnya, imam al-Asy’ari keluar

\footnotetext{
${ }^{21}$ Zulhelmi., h. 4. Lihat juga Abu Zahrah., h. 149.

${ }^{22}$ Havis Aravik, 'Etika Rasionalisme Versus Etika Voluntarisme: Studi Kritis Mu'tazilah Dan Asy’ariyah', Salam: Jurnal Sosial Dan Budaya Syar'i, 5.1 (2018)., h. 16.

${ }^{23}$ Joesoef Sou'yb, Peranan Aliran Iktizal Dalam Perkembangan Alam Pikiran Islam (Jakarta: Pustaka Alhusna, 1982)., h. 24.

${ }^{24}$ Safii, 'Teologi Mu’tazilah: Sebagai Upaya Revitalisasi', Teologia, 25.2 (2014)., h. 5-8.
} 
menemui masyarakat dan naik ke mimbar pada hari Jum'at di Masjid Jami' Bashrah dan beliau pun berkata:

"Barangsiapa yang telah mengenalku, maka sebenarnya ia memang telah mengenalku, dan barangsiapa yang belum mengenalku, maka kini saya memperkenalkan diri. Saya adalah Fulan ibn Fulan. Saya pernah mengatakan bahwa al-Qur'an adalah makhluk, bahwa Allah tidak terlihat oleh Indera penglihatan kelak pada hari kiamat, dan bahwa perbuatan-perbuatan saya tidak baik, maka saya sendirilah yang melakukannya. Kini saya bertaubat dari pendapat seperti itu serta siap untuk menolak pendapat Mu'tazilah dan mengungkap kelemahan mereka (Cetakan tebal dari pemakalah) Selama ini saya telah menghilang dari hadapanmu karena saya sedang berpikir. Menurut pendapat saya, dalil-dalil kedua kelompok itu seimbang. Tidak satupun dalil yang lebih unggul atas dalil yang lain. Kemudian saya memohon petunjuk kepada Allah maka Allah memberikan petunjuk kepada saya untuk meyakini apa yang tertera di dalam kitab saya. Saya akan melepaskan apa yang pernah saya percayai sebagaimana saya akan menanggalkan baju saya ini" 25 .

Aliran ini lahir sebagai reaksi cepat melawan Mu'tazilah dan lebih luas melawan Syi'ah ${ }^{26}$. Di dalam ajaran-ajarannya Abu Hasan al-Asy'ari banyak mengikuti jejak Imam Ahmad ibn Hanbal, beliau mengatakan:

"Pendapat dan keyakinan yang kami percayai ialah berpegang kepada Kitab Allah dan sunnah Nabi serta apa saja yang diriwayatkan dari para sahabat, tabi' in dan para imam hadits. Kami berpegang kepada itu semua dan pendapat yang dipedomani oleh Imam Ahmad ibn Hanbal, serta menjauhi orang-orang yang menentang pendapatnya. Ibn Hanbal adalah seorang imam yang mulia dan pemimpin yang paripurna (Cetakan tebal dari pemakalah). Melalui dirinya Allah menerangkan kebenaran di saat kesesatan sedang merajalela, menunjukkan jalan-Nya, memalingkan para pembuat bid'ah, serta memalingkan kesesatan orang-orang yang sesat dan keraguan orang-orang skeptis. Semoga Allah memberikan rahmat kepadanya sebagai seorang imam yang terkemuka dan tokoh yang arif serta kepada seluruh pemimpin kaum muslimin"27

\footnotetext{
${ }^{25}$ Abu Zahrah., h. 190.

${ }^{26}$ Fazlur Rahman, Revival and Reform in Islam Diterjemahkan Oleh Aam Fahmia Dengan Judul Gelombang Perubahan Dalam Islam: Studi Fundamentalis Islam (Jakarta: Rajawali Press, 2000)., h. 45. Dan lihat juga

27 Ahmad Baso, NU Studies: Pergolakan Pemikiran Antara Fundamentalisme Islam Dan Fundamentalisme Neo-Liberal (Jakarta: Erlangga, 2006)., h. 85.
} 
Dari kutipan ini, kita dapat melihat bahwasanya posisi Imam al-Asy’ari mengikuti jejak tradisi yang dikembangkan oleh Imam Ahmad ibn Hanbal dan kembali menghidupkan metode berpikirnya. ${ }^{28}$ Tetapi KH. Said Aqil Sirajd mengatakan bahwa lahirnya aliran ini sebagai jalan tengah antara pemikiran Mu'tazilah yang sangat liberal dan paham ahlul hadits yang terlalu tekstual. $^{29}$

Dalam perjalanan dan perkembangan pemikiran Islam selanjutnya telah terbagi dalam beberapa aliran kalam yang pertama kali diawali oleh naik dan berkuasanya Umayyah bin Abi Sufyan menjadi khalifah pertama daulah Umayyah yang melakukan penumpahan darah rakyat, merampas harta benda mereka dan berlaku sewenang-wenang dengan dalih bahwa perbuatan kami termasuk bagian dari takdir Allah. ${ }^{30}$ Perbuatan dan tindakan sewenang-wenang yang dilakukan oleh khalifah Umayyah dengan menggunakan politisasi agama (aliran Jabariah), maka bermunculanlah individu atau kelompok-kelompok yang tidak sependapat dengan tindakan penguasa, seperti Ma'bad al-Juhani, Ghaylan al-Dimasyqi, kelompok sufi terkenal di bawah bimbingan Hasan al-Bashri, begitu pula dengan muridnya Washil bin 'Atha' (w. 748), yang mempelopori lahirnya aliran Mu'tazilah yang mempunyai pandangan free will (kehendak bebas) manusia.

Penggugatan terhadap pemerintahan Bani Umayyah inilah, sehingga beberapa aliran kalam bermunculan dalam mengoreksi paham Jabariahnya, salah satunya aliran Mu'tazilah. Mu'tazilah mulai berjaya dan menjadi mazhab resmi di bawah kepemimpinan khalifah alMakmun, al-Mu'tashim dan al-Watsiq. Zaman inilah penerjemahan pengetahuan ke dalam

\footnotetext{
${ }^{28}$ Abu Hasan Al-Asyari belajar dari gurunya Zakariya ibn Yahya al-Saji $(307 \mathrm{H})$ salah seorang murid Ahmad ibn Hanbal. Abu Hasal Al-Asy'ari sezaman dengan Al-Barbahari salah seorang tokoh Hanabilah dari jalur Abu Bakar al-Marmazi. Al-Marwazi salah seorang murid dari Ahmad bin Hanbal dan ia jugalah yang menutup mata gurunya Ahmad bin Hanbal ketika wafatnya. Lihat Teologi Muslim Puritan, h. 83-84. ((referensi utamanya Lihat Ibn Abū Ya'lá, Tabaqāt al-Hanābilah, 2/16. Lihat juga Ibn Taymīyah, Iqāmat al-Dalīl 'alá Ibțāl al-Tahlīl tahqiq: Ḥamdī 'Abd al-Hamīd al-Salafì (Beirut \& Oman: al-Maktab al-Islāmī, 1988), 4/168; al-Dhahabī, Sayr A 'lām al-Nubalā', 14/198. Zakarīyā Ibn Yahyá al-Sājī merupakan ahli Hadis di Basrah. Selain sebagai teolog, ia juga dikenal sebagai ahli ilmu 'ilal (cacat dalam sanad dan matan Hadis). Lihat juga Al-Dhahabī, Tārīkh al-Islām, 24/258. Ibn Taymīyah, al Fatāwá al-Kubrá, 4/168))

${ }^{29}$ Mastuki, Kiai Menggugat: Mengadili Pemikiran Kang Said (Jakarta: Pustaka Ciganjur, 1999)., h. 20.

${ }^{30}$ Benih pertikaian ini telah ada sejak pembunuhan khalifah Utsman bin Affan dan menguat ketika pemerintahan Bani Umayyah. Lihat Majid Fakhry, A Short Introduction to Islamic Philosophys, Theology and Mysticism Diterjemahkan Oleh Zaimul Am Dengan Judul Sejarah Filsafat Islam: Sebuah Peta Kronologis (Bandung: Mizan, 2001)., h. 16.
} 
bahasa Arab terus digalakkan, pengetahuan menjadi berkembang dan masa ini terkenal dengan masa keemasan Islam yang melahirkan beberapa pemikir Islam yang terkenal seperti Abû Yûsuf Ya'qûb al-Kindi (w. 866 M), dan Abû Bakr al-Razi (w. 925/935 M) sebagai platonis Islam terbesar, akan tetapi di sisi lain terdapat juga penentangan yang tidak senang terhadap Mu'tazilah sebagai mazhab resmi diwakili oleh Ahmad Ibn Hanbal (w. 855 M) dengan mengatakan bahwa Kalam Allah bukanlah ciptaan, melainkan kekal abadi sebagaimana halnya zat Allah itu sendiri. ${ }^{31}$

Perdebatan Alqur'an apakah itu qadim atau makhluk di masa ini sangat sengit, sehingga seorang individu yang tidak mengakui Alqur'an sebagaimana statemen Mu'tazilah, maka akan dijebloskan dalam penjara. Inilah beberapa dark side (sisi gelap) zaman Islam yang mengukuhkan salah satu aliran menjadi aliran resmi negara, sama halnya pada zaman daulah Umayyah yang di sokong oleh paham Jabarîah. Akan tetapi, menurut Muhammad 'Abed AlJabiri dalam bukunya Al-Mutsaqqafûna fî al-Hadhârah al-Arabiyah: Mihnah Ibn Hanbal wa Naqbah Ibn Rusyd menulis bahwa persoalan mihnah terhadap Ibn Hanbal adalah persoalan politik, yakni mengapa khalifah Al-Ma'mun dan Al-Mu'tashim mempertanyakan Alqur'an itu qadim atau makhluk?. Persoalan Alqur'an sebagai makhluk diangkat dan menjadi pertanyaan bagi ulama yang tidak sepaham dan bersikap oposan. Hal ini bermula bagaimana khalifah alMa'mun ingin mengamankan wilayah Baghdad yang baru dikuasainya dari saudaranya Khalifah Al-Amin. Dalam sejarah tercatat bahwa wilayah Baghdad dalam era transisi dari khalifah Al-Amin ke khalifah Al-Ma'mun terjadi kekacauan, kemudian muncullah sekelompok orang yang menamakan dirinya sebagai “kelompok amar ma'ruf nahi munkar” yang salah satu tokohnya adalah ahli fiqhi dan hadis terkenal di kota Baghdad, yakni Ahmad Ibn Hanbal.

Ketika khalifah Al-Ma'mun memasuki kota tersebut, kelompok ini tetap tidak mau tunduk kepada khalifah al-Ma'mun karena beberapa sebab, yakni pertama, khalifah AlMa'mun mengangkat Ali Ridha bin Musa al-Kadzim (Imam kedelapan dari Syi'ah Itsna Asyariah) sebagai putra mahkota pada tahun $201 \mathrm{H}$. Kedua, masih langgengnya pertentangan clan antara Bani Hasyim dan Bani Umayyah yang terus meruncing di era kepemimpinan

\footnotetext{
${ }^{31}$ Fakhry., h. 24.
} 
khalifah Al-Ma'mun, Al-Mu'tashim dan Al-Watsiq. Dengan beberapa sebab inilah, maka "kelompok amar ma'ruf nahi munkar" di panggil seperti Al-Izz ibnu Abdu al-Salam, Khalid al-Daryusy, Sahl bin Salamah al-Anshari, Ahmad ibn Hanbal, Sijadah, Qawariri, Muhammad bin Nuh al-Madhrub, dan Ahmad bin Nashr al-Khaza'i, mereka ini ditanyakan mengenai kemakhlukan Alqur'an. Di antara tokoh-tokoh ini, hanya Ahmad ibn Hanbal yang memiliki umur yang panjang, walaupun proses mihnah terhadap dirinya terus dilakukan hingga berjalannya masa kepemimpinan al-Mutawakkil.

Oleh karena itu, persoalan politik sangat dominan dalam persoalan kemakhlukan Alqur'an di zaman ini, dan banyak para ulama fuqaha dan hadis yang mengambil posisi bersebrangan dengan posisi penguasa. Posisi bersebrangan ini tidak hanya berhenti setelah "era Mu'tazilah" runtuh, akan tetapi di zaman al-Mutawakkil, para ulama tetap mengambil sikap oposan, walaupun pemerintahan al-Mutawakkil lebih cenderung ke aliran non-Mu'tazilah dan Syi'ah. ${ }^{32}$ Hal ini terbukti Ahmad ibn Hanbal dengan tetap menjalani tahanan rumahnya sejak khalifah Al-Watsiq dan dilarang keluar rumah bahkan untuk melaksanakan shalat Jum'at dan shalat berjamah. ${ }^{33}$ Peristiwa ini menjadikan Ahmad ibn Hanbal sebagai ulama fiqhi dan hadis yang termasyhur di seluruh dunia Islam karena sikap oposisinya yang tidak mau tunduk dan patuh terhadap kekuasaan yang zalim.

Persoalan politik tidaklah dapat dilepaskan dalam ranah teologis zaman ini. Dengan demikian, membincangkan masalah zat Allah dan kewajiban mentauhidkan, mengagungkan dan menyucikannya tanpa melihat persoalan politik yang melatarbelakanginya, hanya akan membawa ke arah pemahaman yang cenderung sepihak dan tidak utuh. Maka, masalah teologi yang cenderung teosentrisme merupakan bagian dari perselingkuhan politik dan agama yang

\footnotetext{
${ }^{32}$ Pemihakan terhadap Ahl Sunnah wa al-Jama'ah disebabkan untuk menyeimbangi tekanan para komandan perang tentara bangsa Turki yang telah menguasai pemerintahan sejak masa kepemimpinan khalifah Al-Watsiq. Lihat Muhammad 'Abid Al-Jabiri, Al-Mutsaqqafûna Fî Al-Hadhârah Al-Arabiyah: Mihnah Ibn Hanbal Wa Naqbah Ibn Rusyd Telah Diterjemahkan Oleh Zamzam Afandi Abdillah Dengan Judul Tragedi Intelektual: Perselingkuhan Politik Dan Agama (Sleman: Pustaka Alief, 2003)., h. 205.

${ }^{33}$ Ibn Hanbal pernah dipanggil oleh Khalifah al-Mutawakkil agar supaya ia mendukung kekuasaannya, sang khalifah pun merayunya dengan memberikan tempat tinggal istemewa di sekitar istana beserta makanan enak yang diantar atas perintah khalifah. Akan tetapi, bujukan dan rayuan sang khalifah tidaklah mempan, dan membiarkan Ibn Hanbal untuk kembali ke rumahnya sedia kala dengan catatan tidak boleh melakukan aktivitas di luar rumah dan berkomunikasi dengan orang lain, dan ibn Hanbal menjalani tahanan rumahnya hingga meninggal pada tahun 241 H. Lihat Al-Jabiri., h. 206.
} 
banyak ditulis oleh para sejarawan dan teoretis sekte dan aliran sejak generasi abad keempat hijriyah. ${ }^{34}$ Penulisan masalah teologis an sich dengan berbagai doktrinnya di mulai dalam kurun keempat hijriyah.

Perkembangan pemikiran Islam selanjutnya mengalami perkembangan dengan pesat, akan tetapi dalam rangka hanya mempertahankan alirannya masing-masing. Maka janganlah heran, jikalau perdebatan teologi zaman ini lebih banyak membicarakan pengukuhan alirannya atas nama kebenaran sang Pencipta, sehingga persoalan-persoalan sosial mengenai keberlangsungan kehidupan manusia cenderung diabaikan. Hal ini dipaparkan oleh Hassan Hanafi, seorang pemikir Islam:

Para ahli kalam klasik telah membela eksistensi Allah, dengan asumsi bahwa persoalan ketuhanan merupakan sesuatu yang rawan dan sering mendapat serangan. Sedangkan kita dewasa ini membela bumi, karena bumi ini merupakan tempat kita berpijak, tempat mengembangkan sayap, dan kekayaan alam yang melimpah. Allah dengan nash Alqur'an menyatakan bahwa Dia adalah 'Tuhan langit dan bumi', 'Pemelihara langit dan bumi', 'Dialah Tuhan yang di langit, dan Tuhan di bumi'. 35

Sebagaimana yang telah dikatakan oleh Prof. Amin Abdullah bahwa teologi bukanlah agama. Teologi adalah hasil rumusan pikiran manusia dengan waktu dan situasi sosial yang ada, sehingga ia menawarkan bahwa istilah ilmu kalam diganti dengan istilah falsafah kalam dengan pengertian bahwa falsafah kalam membuat orang tidak lagi segan untuk mempertanyakan ulang, meninjau kembali gagasan-gagasan pemikiran ketuhanan yang terjadi pada abad tengah dan klasik. ${ }^{36}$ Perubahan teologi menjadi falsafah kalam dapat juga berarti bahwa teologi yang sifatnya sakral menjadi profan. Falsafah kalam menjadi identitas lain dari teologi yang cenderung antroposentrisme.

Mandegnya teologi antroposentrisme (sunnatullah) ${ }^{37}$ ke arah teologi kehendak mutlak Tuhan ala al-Asy'ariyah di zaman pertengahan membawa konsekuensi terhadap

\footnotetext{
34 Al-Jabiri., h. 191.

${ }^{35}$ Hassan Hanafi, Min Al- 'Aqīdah Ilā Al-Tsawrah Al-Muqaddimāt Al-Nazharīyah Diterjemahkan Oleh Asep Usman Ismail Dengan Judul Dari Akidah Ke Revolusi (Jakarta: Paramadina dan Dian Rakyat, 2010)., h. xlvi.

${ }^{36}$ Amin Abdullah, Studi Agama: Normativitas Atau Historisitas? (Yogyakarta: Pustaka Pelajar, 1999)., h. 48 .

${ }^{37}$ Harun Nasution membagi sejarah Islam ke dalam tiga zaman, yakni zaman klasik (650-1250 M), zaman pertengahan (1250-1800 M) dan zaman modern (1800-sampai sekarang). Teologi sunnatullah mengalami kemunduran diganti dengan teologi Jabarîah yang mempunyai ciri-ciri sebagai berikut kedudukan akal yang rendah; ketidakbebasan manusia dalam kemauan dan perbuatan; kebebasan berpikir yang diikat dengan banyak
} 
perkembangan Islam dan pengetahuan pada masa berikutnya. Pertarungan dalam mengukuhkan aliran beserta doktrin ajarannya terus berjalan, hingga muncullah Abu Hasan alAsy'ari sebagai tokoh penggagas lahirnya teori $a l-k a s b^{38}$ merupakan jalan tengah antara aliran Jabarîah dan Mu'tazilah/Qadariah. Teori ini memberikan kehendak manusia untuk berbuat, akan tetapi daya untuk berkehendak itu juga berasal dari Allah swt. Banyak kalangan pemikir Islam yang memasukkan Abu Hasan al-Asy'ari dalam kubu Jabarîah, walaupun sebenarnya aliran ini mempunyai perbedaan dengan teori fatalismenya Jabarîah.

Dalam sejarah Islam, gagasan Abu Hasan al-Asy'ari mendapat ruang dan perhatian dalam kekuasaan daulah Abbasiyah, khususnya di bawah naungan khalifah al-Qadir (berkuasa 381-422 H/991-1031 M) dan anaknya al-Qa'im (berkuasa 422-677 H) deklarasi al-I'tiqad alQadiri, pemahaman ini terus dilanjutkan oleh para murid, seperti al-Baqillani (w. $403 \mathrm{H}),{ }^{39}$ alJuwaini (w. 478 H) dan al-Gazali (w. 595 H). Dengan bacaan filsafat Aristoteles dan tradisi gnosis dari neo-Platonisme, al-Gazali melakukan pengukuhan aliran al-Asy'ariyah. ${ }^{40}$ Masa inilah menjadi masa-masa kejayaan aliran al-Asy'ariyah hingga mampu bertahan hingga detik ini dengan konsep kasb-nya, walaupun di zaman selanjutnya muncullah Ibn Taimiyah sebagai pelopor gerakan pembaruan dari pengikut Hanabilah.

Teologi al-Asy'ariyah berkembang pesat di zaman pemerintahan Saljuk di Baghdad dan teologi ini diajarkan di Universitas al-Nizhamiyah oleh Hujjat al-Islam Imam al-Gazalî

dogma; ketidakpercayaan kepada sunnatullah dan kausalitas; terikat kepada arti tekstual dari Alqur'an dan Hadis, dan statis dalam sikap dan berpikir. Lihat Harun Nasution, Islam Rasional: Gagasan Dan Pemikiran (Bandung: Mizan, 1998)., h. 116.

${ }^{38}$ Dalam kitabnya al-Luma, al-Asy'ari mengemukakan tiga bentuk kata yang erat kaitannya dengan kata $a l-k a s b$, yaitu al-iktisab, al-muktasib, dan al-kasb. Kata al-kasb dan al-iktisab pada dasarnya menggambarkan perbuatan manusia yang diwujudkan dengan daya yang diciptakan. Lanjutnya, manusia mempunyai daya, akan tetapi daya itu tidak bersifat efektif. Lihat Nukman Abbas, Al-Asy'ari: Misteri Perbuatan Manusia Dan Takdir Tuhan (Jakarta: Erlangga, 2017)., h. 213-214.

${ }^{39} \mathrm{Al}$-Baqillânî hanya mengikuti al-Asy'arī dalam tiga masalah yaitu masalah melihat Tuhan, janji dan ancaman Tuhan, dan konsep imam dan hari akhirat. Al-Baqillânî lebih dekat ke Mu'tazilah disebabkan situasi sosial-politik di masanya berada dalam dinasti Buwaihi yang merupakan masa bangkitnya kembali kaum Mu'tazilah. Ia mempunyai hubungan erat dengan penguasa dinasti Buwaihi sehingga ia dipercaya untuk mengajar serta menulis Kitâb al-Tamhîd untuk putra 'Adud al-Daulah al-Buwaihî. Lihat Ilhamuddin, Pemikiran Kalam AlBaqillânî: Studi Tentang Persamaan Dan Perbedaannya Dengan Al-Asy'arî (Yogyakarta: Tiara Wacana, 1997)., h. 138.

$$
{ }^{40} \text { Baso., h. } 90 .
$$


(w. $505 \mathrm{H} / 1111 \mathrm{M}){ }^{41}$ Kuatnya pengaruh aliran al-Asy'ariyah hingga saat ini tak bisa dilepaskan dari peranan dan andil Imam al-Gazalî sebagai guru besar di universitas tersebut dan juga juru bicara raja Nizham al-Mulk dalam menggempur gerakan Syi'ah Isma'ili dan para filsuf yang ingin mengambil alih kekuasaan.

Perkembangan teologi al-Asy'ariyah menjadi kuat dan kukuh di tangan al-Gazalî setelah menyerang para filsuf Islam dan menawarkan sufisme sebagai jalan menuju Tuhan, khususnya kritik terhadap Ibn Sina sehingga perkembangan pemikiran Islam seolah berhenti berputar. Akan tetapi, serangan Imam al-Gazali tidaklah menjadi satu-satunya sebab dalam keruntuhan pemikiran Islam, memang perkembangan pemikiran Islam di dunia timur mengalami kemandegan, di sisi barat dunia Islam, khususnya wilayah Andalusia bermunculah pemikir sekaligus filsuf Islam, yakni Ibn Rusyd yang juga mengkritik balik Imam al-Gazalî. Kritik Ibn Rusyd tidak menggoyahkan pemahaman umat Islam akan buruknya belajar filsafat, hingga dewasa ini. Hal ini diperparah dengan ambruknya kerajaan Abbasiyah di Baghdad oleh serangan Hulagu Khan pada tahun 656 H/1258 M. ${ }^{42}$ Dalam ranah inilah, teologi teosentrisme menaik, berkembang dan banyak dianut oleh umat Islam kala itu dengan dalih bahwa pintu ijtihad telah tertutup.

Atas pembacaan historis mengenai lahirnya gagasan Abu Hasan al-Asy’ari dengan teori kasb-nya terhadap manusia yang berkehendak, belumlah sepenuhnya menjadikan Ahl alSunnah wa al-Jama'ah (ASWAJA) sebagai mazhab resmi sebagaimana yang diketahui secara umum, yakni menganut teologi Asy'ariyah dan Maturidiyah, menganut fiqh Imam empat mazhab, dan menganut tasawuf al-Gazâlî dan Junaid al-Baqdâdî. Pengakuan secara eksplisit mengenai adanya paham ASWAJA baru dikemukakan oleh al-Zabidi bahwa yang dimaksud adalah pengikut al-Asy'arî dan Maturidi. ${ }^{43}$ Hal ini berarti pemahaman ASWAJA baru dikenal setelah wafat tokoh-tokoh penggagas tersebut.

\footnotetext{
${ }^{41}$ Baso., h. 168.

${ }^{42}$ Syafiq A. Mughni, Dinamika Intelektual Islam Pada Abad Kegelapan (Surabaya: LPAM, 2002)., h. 12.

${ }^{43}$ Ahmad Zahro, Tradisi Intelektual NU (Yogyakarta: LKiS, 2004)., h. 48.
} 
Abu Hasan al-Asy'ari dan Imam al-Maturidi telah memperkenalkan jalan moderat (atTawassut) dalam melerai perpecahan dan meredam pertikaian antara sekte yang satu dengan sekte yang lainnya dengan memperkenalkan konsep al-kasb (daya) manusia dalam bertindak. Jalan tengah antara aliran Jabariyah dan Qadariyah/Mu'tazilah, Imam al-Asy'ari menjelaskan bahwa dengan al-kasb tersebut menjadikan manusia selalu berusaha secara kreatif dalam kehidupannya, tanpa melupakan bahwa Tuhanlah yang menentukan semuanya. Sedangkan Imam al-Maturidi mengatakan bahwa kekuasaan dan kehendak mutlak Tuhan dibatasi oleh Tuhan sendiri. Walaupun manusia diberi kekuasaan dengan dayanya untuk berbuat kehendaknya, akan tetapi perbuatan manusia tetap diciptakan oleh Tuhan. Hal ini mengindikasikan bahwa, dalam perbuatan manusia adalah perbuatan bersama, Tuhan yang mencipta dan manusia mengkasabnya. Dengan demikian, kedua aliran ini membolehkan manusia untuk bertindak dan berkehendak, akan tetapi dalam bertindak tidak boleh melupakan Allah swt.

Begitu pula dalam kaitan antara akal dan wahyu dalam kehidupan ini, kedua aliran ini juga mengambil posisi tengah antara akal dan wahyu. Menurut al-Asy'ariyah, rasionalitas tetap diakui dan dihormati, akan tetapi agar kerja-kerja akal tidak menyimpang, maka manusia harus mengembalikannya di bawah kontrol wahyu. Hal berbeda diungkapkan oleh aliran alMaturidiyah dalam penggunaan akal bahwa suatu kesalahan apabila berhenti berbuat pada saat tidak terdapat nash, begitu pun juga salah apabila larut dalam menggunakan akal (rasio). Oleh karena itu, wahyu mesti diterima penuh, apabila terdapat perbedaan antara akal dan wahyu, maka akal harus berperan mentakwilkannya. ${ }^{44}$

Pemahaman sifat dan zat Allah swt, kedua aliran ini mengatakan bahwa Allah memiliki sifat, walaupun sifat tidak sama dengan zat-Nya. Allah swt mengetahui bukan dengan zat-Nya, akan tetapi dengan sifat ilmu-Nya. Selanjutnya, Imam al-Asy'ari memperkenalkan ajaran keberadaan sifat-sifat Allah swt (sifat wajib dua puluh bagi Allah swt), akan tetapi dalam perkembangan dikemudian hari para muridnya Imam al-Baqillânî dan Imam al-Juwainî tidak

\footnotetext{
${ }^{44}$ Masyhudi Muchtar, Aswaja An-Nahdliyah: Ajaran Ahlusunnah Wa Al-Jama'ah Yang Berlaku Di Lingkungan Nahdlatul Ulama (Surabaya: Khalista, 2009)., h. 16.
} 
mengapresiasi ajaran gurunya. ${ }^{45} \mathrm{Hal}$ ini mengindikasikan bahwa kedua Imam ini tidak membakukan ajarannya tentang sifat wajib Allah swt.

Sedangkan yang terakhir, kedua Imam teolog ini telah melakukan "kritik sosial" terhadap penguasa yang meresmikan sebuah aliran keagamaan dalam kekuasaannya. ${ }^{46}$ Kedua Imam ini, menolak aliran yang memaksakan ajaran-ajarannya kepada orang lain dengan cara keras dan menyelesaikan persoalan dengan cara kekerasan.

\section{Penutup}

Berdasarkan rumusan masalah, uraian dan pembahasan yang telah dikemukakan sebelumnya dapatlah dikemukakan kesimpulan bahwa munculnya pertama kali paham dan aliran akidah dalam Islam mempunyai banyak faktor, diantaranya (1). Faktor politik. Terbunuhnya khalifah ketiga umat Islam Utsman bin Affan dikemudian hari menyisakan problema, yang puncaknya adalah terpecahnya umat Islam kedalam beberapa kelompok. (2) Faktor identitas. Faktor ini juga memberi andil dalam "perpecahan" umat Islam. Hal ini disebabkan para umat Islam kala itu lebih memilih "kepala suku atau orang terkuat dalam sukunya" dalam menentukan kelompok yang dilabuhkan untuk didukung, sehingga pilihan kelompoknya cenderung kesukuan atau kewilayahan.

Dari beberapa faktor inilah, sehingga memunculkan beberapa paham dan aliran akidah dalam Islam, seperti aliran Khawarij, Murji'ah, Syi'ah, Mu'tazilah dan Asy'ariyah. Menyajikan tulisan ini sangatlah urgen, agar dapat dijadikan pelajaran bahwa hina-menghina golongan, saling mencaci aliran dan kafir-mengkafirkan paham merupakan hal yang tidak elok dan seharusnya patut dihindari.

${ }^{45}$ Sifat wajib 20 Allah swt dibakukan oleh Imam Abu Abdillah as-Sanusi (w. 895 H) dalam karyanya alAqai'd As-Sanusiyah al-Kubra. Kemudian karya ini dieksposisi oleh Ad-Dasuki dari Mesir dalam karyanya Uтти al-Barahin pada abad ke-19. Lihat Said Aqil Siradj, Tasawuf Sebagai Kritik Sosial (Bandung: Mizan, 2006)., h. 430.

${ }^{46}$ Muchtar., h. 18. 


\section{Daftar Pustaka}

Abbas, Nukman. Al-Asy'ari: Misteri Perbuatan Manusia Dan Takdir Tuhan (Jakarta: Erlangga, 2017.

Abdullah, Amin. Studi Agama: Normativitas Atau Historisitas? (Yogyakarta: Pustaka Pelajar, 1999.

Abu Zahrah, Muhammad. Tarikh Al-Madzahib Al-Islamiyyah Diterjemahkan Oleh Abd. Rahman Dan Ahmad Qarib Dengan Judul Aliran Politik Dan'Aqidah Dalam Islam. Jakarta: Logos, 1996.

Abu Zaid, Nashr Hamid, Al-Ittijah Al- 'Aqli Fi Al-Tafsir: Dirasah Fi Qadhiyyat Al-Majaz Fi Al-Qur'an 'Inda Al-Mu'Tazilah Diterjemahkan Oleh Abdurrahman Kasdi Dan Hamka Hasan Dengan Judul Menalar Firman Allah: Wacana Majaz Dalam Al-Qur'an Menurut Mu'tazilah. Jakarta: Mizan, 2003.

Al-Jabiri, Muhammad 'Abid. Al-Mutsaqqafûna Fî Al-Hadhârah Al-Arabiyah: Mihnah Ibn Hanbal Wa Naqbah Ibn Rusyd Telah Diterjemahkan Oleh Zamzam Afandi Abdillah Dengan Judul Tragedi Intelektual: Perselingkuhan Politik Dan Agama. Sleman: Pustaka Alief, 2003.

Analiansyah, 'Peran Akal Dan Kebebasan Bertindak Dalam Filsafat Ketuhanan Mu'tazilah', Jurnal Subtantia, 15.1, 2013.

Aravik, Havis, 'Etika Rasionalisme Versus Etika Voluntarisme: Studi Kritis Mu'tazilah Dan Asy'ariyah', Salam: Jurnal Sosial Dan Budaya Syar'i, 5.1, 2018.

Asmuni, M. Yusran. Ilmu Tauhid. Jakarta: Raja Grafindo Persada, 1994.

Asy-Syahrastani. Al-Milal Wa Nihal Alih Bahasa Oleh Asywandie Syukur. Surabaya: Bina Ilmu, 2000.

Baso, Ahmad. NU Studies: Pergolakan Pemikiran Antara Fundamentalisme Islam Dan Fundamentalisme Neo-Liberal. Jakarta: Erlangga, 2006.

Cawidu, Harifuddin. Konsep Kufr Dalam Al-Qur'an: Suatu Kajian Teologis Dengan Pendekatan Tafsir Tematik, 1st edn. Jakarta: Bulan Bintang, 1991.

Fakhry, Majid. A Short Introduction to Islamic Philosophys, Theology and Mysticism Diterjemahkan Oleh Zaimul Am Dengan Judul Sejarah Filsafat Islam: Sebuah Peta Kronologis. Bandung: Mizan, 2001.

Goldziher, Ignaz. Introduction to Islamic Theologi and Law. New Jersey: Princeton University Press, 1981.

Hanafi, Hassan. Min Al-'Aqūdah Ilā Al-Tsawrah Al-Muqaddimāt Al-Nazharīyah Diterjemahkan Oleh Asep Usman Ismail Dengan Judul Dari Akidah Ke Revolusi. Jakarta: Paramadina dan Dian Rakyat, 2010.

Hashem, O. Saqifah Suksesi Sepeninggal Rasulullah Saw: Awal Perselisihan Umat. Depok: YAPI, 1989.

Ilhamuddin. Pemikiran Kalam Al-Baqillânî: Studi Tentang Persamaan Dan Perbedaannya Dengan Al-Asy'arî. Yogyakarta: Tiara Wacana, 1997.

Izutsu, Toshihiko. The Concept of Belief in Islamic Theology: A Semantical Analysis of Iman 
Anda Islam Diterjemahkan Oleh Agus Fahri Husein Dengan Judul Konsep Kepercayaan Dalam Teologi Islam: Analisis Semantik Iman Dan Islam. Yogyakarta: Tiara Wacana, 1994.

Mastuki. Kiai Menggugat: Mengadili Pemikiran Kang Said. Jakarta: Pustaka Ciganjur, 1999.

Muchtar, Masyhudi. Aswaja An-Nahdliyah: Ajaran Ahlusunnah Wa Al-Jama'ah Yang Berlaku Di Lingkungan Nahdlatul Ulama. Surabaya: Khalista, 2009.

Mughni, Syafiq A. Dinamika Intelektual Islam Pada Abad Kegelapan. Surabaya: LPAM, 2002. Nasution, Harun. Islam Rasional: Gagasan Dan Pemikiran. Bandung: Mizan, 1998.

—, Teologi Islam: Aliran-Aliran Sejarah Analisa Perbandingan. Jakarta: UI Press, 1986.

Rahman, Fazlur. Revival and Reform in Islam Diterjemahkan Oleh Aam Fahmia Dengan Judul Gelombang Perubahan Dalam Islam: Studi Fundamentalis Islam. Jakarta: Rajawali Press, 2000.

Safii, 'Teologi Mu’tazilah: Sebagai Upaya Revitalisasi’, Teologia, 25.2, 2014.

Siradj, Said Aqil. Tasawuf Sebagai Kritik Sosial. Bandung: Mizan, 2006.

Sou'yb, Joesoef. Peranan Aliran Iktizal Dalam Perkembangan Alam Pikiran Islam. Jakarta: Pustaka Alhusna, 1982.

Zahro, Ahmad. Tradisi Intelektual NU. Yogyakarta: LKiS, 2004.

Zulhelmi, 'Epistemologi Pemikiran Mu'tazilah Dan Pengaruhnya Terhadap Perkembangan Pemikiran Islam Di Indonesia', Intizar, 20.1, 2014. 